\title{
Comparison of the cognitive performance of elderly caregivers with and without chronic pain*
}

\section{Comparação do desempenho cognitivo de idosos cuidadores com e sem dor crônica Comparación del desempeño cognitivo de ancianos cuidadores con y sin dolor crónico}

\author{
Marielli Terassi ${ }^{1}$, Estefani Serafim Rossetti ${ }^{1}$, Karina Gramani-Say ${ }^{2}$, Tiago da Silva Alexandre ${ }^{2}$, Priscilla Hortense ${ }^{3}$, Sofia \\ Cristina lost Pavarini ${ }^{2}$
}

How to cite this article:

Terassi M, Rossetti ES, Gramani-Say K, Alexandre TS, Hortense P, Pavarini SCI. Comparison of the cognitive performance of elderly caregivers with and without chronic pain. Rev Esc Enferm USP. 2017:51:e03260. DOI: http://dx.doi.org/10.1590/S1980-220X2016023203260

* Extracted from the dissertation "Associação entre chronic pain e cognição em idosos cuidadores", Universidade Federal de São

Carlos, Departamento de Enfermagem, 2015.

${ }^{1}$ Universidade Federal de São Carlos,

Departamento de Enfermagem,

Programa de Pós Graduação em

Enfermagem, São Carlos, SP, Brazil.

${ }^{2}$ Universidade Federal de São Carlos,

Departamento de Gerontologia,

São Carlos, SP, Brazil.

${ }^{3}$ Universidade Federal de São Carlos,

Departamento de Enfermagem,

São Carlos, SP, Brazil.

\begin{abstract}
Objective: Understanding and characterizing chronic pain in elderly caregivers, verifying the cognitive performance of the elderly of the sample and verifying whether there is difference in the cognitive performance of elderly caregivers with and without chronic pain. Method: Participants were people aged 60 years or older who lived with another elderly person in the same household and who were registered in Family Health Units. Data collection took place at participants' homes. Pain was assessed by the EMADOR and cognition was assessed by ACE-R. Statistical analyzes were performed using Shapiro-Wilk's and Mann-Whitney U tests. Results: The study included 187 elderly caregivers with chronic pain and 133 without chronic pain, with a higher frequency of women. Chronic pain was present in $58.4 \%$ of the participants. Regarding the sociodemographic variables, there was no difference between the groups except for the gender variable $(p=0.025)$. No difference was found in cognitive performance among the elderly with chronic pain and those without chronic pain for any domain of the ACE-R instrument. Conclusion: The results contradicted the initial hypothesis that there would be a difference between the groups; however, there is a gap in the scientific knowledge on chronic pain and cognition, especially in elderly caregivers, opening perspectives for future investigations.
\end{abstract}

\section{DESCRIPTORS}

Aged; Caregivers; Chronic Pain; Cognition; Geriatric Nursing. 


\section{INTRODUCTION}

The growth of the elderly population has been happening in an accelerated way throughout the world. Increasing age can lead to a progressive loss of autonomy, resulting in the need for care performed by other people. Caregivers are individuals who dedicate themselves to the care; they can be family members or people hired for this purpose ${ }^{(1)}$.

Several studies indicate that family members are the main caregivers for the elderly, however, with the demographic transition and changes in family dynamics, the number of older persons who perform the role of primary caregiver of another elderly family member has increased over the years ${ }^{(1-2)}$. By taking on the responsibility of providing care, caregivers can modify their life routine, they increase their work overload and become more susceptible to the presence of comorbidities, with chronic pain being among them ${ }^{(2-3)}$.

Elderly caregivers with chronic pain may present greater difficulty performing activities of daily living, negatively influencing the care they provide to another elderly person and self-care; moreover, the presence of chronic pain may compromise their cognitive ability and their behavioral and social skills. Individuals with pain may have a higher prevalence of depression symptoms, sleep disorders, and increased use of medications ${ }^{(4)}$.

Chronic pain is often present among the elderly, resulting in serious and potentially debilitating consequences, demonstrating the importance of consistent pain analyses, assessing the individual's symptoms, functional status and clinical history, as well as the location and timing of pain onset. For an effective evaluation, one must rely on a description by the patient, since the pain is subjective in nature and only the individual can describe how it is being perceived. Other manifestation forms such as crying, grunting/moaning, shouting and protecting specific parts of the body should also be evaluated, especially in elderly with cognitive and speech impairment ${ }^{(5)}$.

According to the International Association for the Study of Pain (IASP) $)^{(6)}$, pain is considered to be an "unpleasant sensory and emotional experience that arises or is described in terms of actual or potential tissue damage". It can trigger negative interference in daily activities and in the quality of life of the individuals, in addition to influencing cognitive $\operatorname{aspects}^{(7)}$.

Pain is a stimulus capable of affecting the dynamic state of the encephalon, since the neural systems involved in cognition are also closely linked to modulation and perception systems of pain $^{(7-8)}$. This interaction between neural structures impairs the speed with which information reaches the brain and the processing capacity of this information, predisposing patients with chronic pain to cognitive deficit ${ }^{(7-8)}$.

A study reviewed clinical and preclinical studies investigating cognitive function in subjects with pain in an attempt to understand whether chronic pain negatively affects cognition. From the results, the authors considered that there are strong signs that pain harms/affects cognitive domains, evidencing the superposition of neuroanatomic and neurochemical substrates involved in pain and cognition ${ }^{(8)}$.
Other studies have also revealed worse outcomes in patients with chronic pain in cognitive tests and learning ability when compared to the control group ${ }^{(9-10)}$, demonstrating both in people and laboratory animals that the presence of chronic pain causes functional alterations in cortical and subcortical structures, including the medial prefrontal cortex, the thalamus, the amygdala and the anterior cingulate cortex, areas that are related to learning, memory, fear, and emotional responses ${ }^{(8-9)}$.

Studies investigating the relationship between cognition and chronic pain in the elderly population have observed worse cognitive test results in the group with chronic pain, demonstrating an association between these two variables in this population ${ }^{(10-12)}$. However, as previously noted, there are few studies that evaluate this relationship, and no studies investigating these variables in the context of elderly caregivers were found in the literature, thus justifying the importance of studying this issue since negative impacts caused by chronic pain in the lives of these people can not only affect their health, but also the health of the elderly who they are caring for.

It is important to emphasize that the present study aims at investigating elderly caregivers in seeking to understand how the relationship between pain and cognition occurs in elderly people who care for other elderly people, since some studies have indicated a negative relationship between these two variables in the elderly ${ }^{(10-12)}$. The caregiver role leads to an increase in overload/burden and stress, which may contribute to the onset of pain ${ }^{(13)}$, and as already discussed, chronic pain may contribute to worse cognitive performance. Our aim is to understand how the relationship between pain and cognitive performance occurs in elderly caregivers with the purpose of analyzing the influence of pain on cognition when the fact of being an "elderly caregiver" is involved.

Thus, the objectives of this study were to: understand and characterize chronic pain in elderly caregivers, to verify cognitive performance of the elderly in the sample and to observe whether there is a difference in the cognitive performance of elderly caregivers with and without chronic pain.

\section{METHOD}

This is a quantitative cross-sectional, observational and analytical study carried out in the city of São Carlos-SP. The population was composed of elderly people living in the urban and rural areas covered by all the Family Health Units (Unidades de Saúde da Familia - USF) of the municipality.

As inclusion criteria, the participant had to be enrolled in a Family Health Unit, be 60 years old or older and provide primary care to another elderly person residing in the same household. Individuals who were not at home after three contact attempts, had passed away, changed address, or those suffering from acute pain at the time of the interview - as we understood that pain could be a bias for cognitive analysis, were excluded. Exclusion criteria also included the situations where two elderly individuals were equally dependent or equally independent for activities of daily living. In this study, chronic pain was considered as continuous or recurrent pain lasting for 6 months or more ${ }^{(14)}$. 
Lists made available by the USF were used for identifying the participants, where the names and addresses of all the elderly people who lived with at least one older person were included. All households were visited, totaling 594 residences.

Performance evaluation questionnaires for basic and instrumental activities of daily living were used to identify elderly caregivers to be included in the study. The elderly with the best performance in the sum of both instrument scores was considered to be an elderly caregiver, and the elderly with the lower score to be the one who received the care. The Basic Activities of Daily Living Scale (BADL) ${ }^{(15)}$ was used to evaluate performance in basic activities, while the Instrumental Activities of Daily Living Scale (IADL) ${ }^{(16)}$ was used to evaluate performance in instrumental activities. Both scales were validated for the Brazilian context. All the participants of this study performed at least one of the basic activities (feeding, bathing, dressing, urinary and fecal continence) or instrumental activities (such as going to a doctor appointment, showering, shopping) considered as the caregiver, therefore, the individual who performed one of these activities for the other elderly person.

After applying inclusion and exclusion criteria, the final sample consisted of 320 elderly caregivers, representing $63.4 \%$ of the total population of elderly caregivers enrolled in the USF. Sixty-nine (69) elderly people were excluded due to not being at home after up to three contact attempts, 26 due to death, 28 due to change of address, 84 due to refusal, 31 due to reporting acute pain and 36 due to the situation in which the two elderly were equally dependent or equally independent for the activities of daily living.

The evaluations took place in the homes of the elderly through individual interviews, carried out by properly trained postgraduate students. Data collection was carried out from April to November 2014.

A questionnaire designed by the researchers was used after having undergone face and content validation for sociodemographic characterization (gender, age, family income, marital status and education level), characterization of the care provided and health status (familial relationship, daily hours spent with care, how long have they been providing care, and number of medications). Pain was assessed by the Multidimensional Pain Evaluation Scale $(E M A D O R)^{(17)}$, which used ten descriptors for chronic pain corresponding to the three qualitative dimensions of pain (sensory dimension, affective dimension and evaluative dimension); by the Numerical Pain Intensity Scale, where the person should report the intensity of pain in the previous week ( 0 meaning absence of pain, 10 meaning unbearable pain and values ranging from 1 to 9 , meaning intermediate pain intensities); and by a body diagram, in which the participant visually indicates the sites affected by pain. The intensity was classified as 0 corresponding to the absence of pain in the previous week, 1 to 3 as weak pain, 4 to 6 as moderate pain, 7 to 9 as intense pain and 10 as unbearable pain ${ }^{(18)}$. It is noteworthy that the participants were able describe the absence of pain in the previous week, but could report pain from previous weeks.

The Addenbrooke Cognitive Examination - Revised (ACE-R) was used for evaluating cognitive performance with the aim of evaluating five cognitive domains: attention and orientation, memory, verbal fluency, language and visuospatial abilities. The overall ACE-R score ranges from 0 to 100 points, distributed among the five domains: attention/ orientation (18 points), memory (26 points), verbal fluency (14 points), language (26 points) and visuospatial skills (16 points) ${ }^{(19)}$. We chose to use the median according to education level for the cut-off score of the ACE-R instrument, considering the high percentage of elderly with low educational level and the lack of a standard in the literature for this profile in the population. Thus, the following medians were considered: illiterates: 39 ; 1 -4 years of education: 62 ; 5-8 years of education: 78; 9 years of education or more: 83 .

The Geriatric Depression Scale (GDS-15) was used to evaluate depression symptoms, which aims to assess depression symptoms in the elderly. It is composed of 15 dichotomous "yes" or "no" questions. Scores ranging from 0 to 5 represent patients withoutalterations, 6 to 10 as having mild depression symptoms, and 11 to 15 as severe symptoms of depression ${ }^{(20)}$.

A translated and validated version of the Zarit Caregiver Burden Interview (ZBI) for the Brazilian culture was used to evaluate the burden of care provided by the elderly. The instrument consists of 22 likert-type response questions with the answer options: "Never", "Rarely", "Sometimes", "Often" and "Always". Each response score ranges from 0 to 4, where 0 -Never and 4-Always. The sum of the questions can vary from 0 to 20 points, in which the caregiver is characterized as having a mild burden; between 21 and 40 points, characterized as moderate burden; between 41 and 60 points, as moderate to severe burden; and between 61 and 88 points as severe burden ${ }^{(21)}$.

The present study was authorized by the Municipal Health Department of São Carlos (Opinion Number 68 of September 20,2013) and approved by the Human Research Ethics Committee of the Federal University of São Carlos (UFSCar) (Opinion Number 517,182 of January 29, 2014).

A database was created in the Epidata 3.1 software for data analysis. Two independent and blinded typists entered data. After double entry validation, the data were then exported to the Stata $10^{\circledR}$ application for Windows. Data normality was verified through the Shapiro-Wilk's test. The t-test was used for variables with normal distribution (number of medications and fluency domain of the ACE-R instrument), whereas the Mann-Whitney $U$ test for independent samples was used for the non-parametric variables. The level of significance was set at $5 \%$ for all statistical tests.

\section{RESULTS}

Three hundred and twenty (320) elderly caregivers participated in the study, divided into two groups: elderly with chronic pain (WP), totaling 187 participants (58.4\%), and elderly without chronic pain (NP), totaling 133 participants $(41.5 \%)$.

Comparing the sociodemographic variables between the groups with pain and without pain, a statistically significant difference was only observed in relation to the female gender. Table 1 shows the distribution of sociodemographic variables according to the groups. 
Table 1 - Distribution of the sociodemographic variables of the elderly caregiver groups with pain and without pain - São Carlos, SP, Brazil, 2016.

\begin{tabular}{|c|c|c|c|}
\hline Variables & Chronic pain $(n=187)$ & Without chronic pain $(n=133)$ & $\mathbf{P}$ \\
\hline \multicolumn{4}{|l|}{ Gender } \\
\hline Female & $80.7 \%$ & $69.9 \%$ & \multirow{2}{*}{0.025} \\
\hline Male & $19.2 \%$ & $30.8 \%$ & \\
\hline $\begin{array}{l}\text { Age (median) } \\
\text { Variation (min.-max.) }\end{array}$ & $\begin{array}{c}67 \\
(60-95)\end{array}$ & $\begin{array}{c}69 \\
(60-98)\end{array}$ & \multirow{4}{*}{0.116} \\
\hline 60 to 69 years old & $62.5 \%$ & $52.6 \%$ & \\
\hline 70 to 79 years old & $26.8 \%$ & $37.6 \%$ & \\
\hline$\geq 80$ years old & $10.7 \%$ & $9.8 \%$ & \\
\hline Family Income* (median) & 2.6 & 2.5 & \\
\hline$\geq 1$ to 3 & $59.8 \%$ & $58.5 \%$ & \multirow{3}{*}{0.255} \\
\hline & $35.8 \%$ & $33.1 \%$ & \\
\hline Not reported & $8.49 \%$ & $8.4 \%$ & \\
\hline Marital Status & $88.7 \%$ & $90.9 \%$ & \multirow{3}{*}{0.522} \\
\hline Married/conjugal life & $11.3 \%$ & $9.1 \%$ & \\
\hline Not married/without partner & & & \\
\hline Education level** (median) & 4 & 3 & \multirow{6}{*}{0.214} \\
\hline Variation (min.-max.) & $(0-17)$ & $(0-19)$ & \\
\hline Illiterate & $14.4 \%$ & $21.8 \%$ & \\
\hline 1 to 4 years & $64.1 \%$ & $62.5 \%$ & \\
\hline 5 to 9 years & $9.7 \%$ & $9.0 \%$ & \\
\hline 10 or more years & $11.8 \%$ & $6.7 \%$ & \\
\hline
\end{tabular}

* Median family income in minimum wages (minimum wage referring to the year 2014). ${ }^{* *}$ Median education level in years of studying.

Regarding the care variables, it was observed that $84.2 \%(\mathrm{n}=112)$ of the participants of the group with pain provided care to their spouse, and $7.5 \%(\mathrm{n}=14)$ to their father/mother. Similar results were observed in the group without chronic pain, where $85 \%(\mathrm{n}=159)$ cared for their spouse, and $7.5 \%(\mathrm{n}=10)$ for the father/mother. Table 2 presents the characteristics of care and health status of each group.

Table 2 - Distribution of the health and care variables of the elderly caregiver groups with pain and without pain - São Carlos, SP, Brazil, 2016.

\begin{tabular}{lcc}
\hline Variables & With pain $(\mathbf{n}=\mathbf{1 8 7})$ & Without pain $(\mathbf{n}=\mathbf{1 3 3})$ \\
\hline Number of medicines (median) & 3.6 & 2.3 \\
$\quad$ None & $7.5 \%$ & $18 \%$ \\
1 to 4 & $62.5 \%$ & $67 \%$ \\
5 or more & $30 \%$ & $15 \%$ \\
Care time in years (median) & 5 & 4 \\
$<1$ year & $19.5 \%$ & $22.7 \%$ \\
1 to 4 years & $24.9 \%$ & $31.9 \%$ \\
5 to 9 years & $19.5 \%$ & $21.8 \%$ \\
$\geq 10$ years & $36.1 \%$ & $23.6 \%$ \\
Care time per day (hours) (median) & 4.5 & 4 \\
1 to 4 hours & $50 \%$ & $51.7 \%$ \\
5 to 9 hours & $26.9 \%$ & $24 \%$ \\
$\quad 10$ hours & $23.1 \%$ & $24 \%$ \\
Depression symptoms & & \\
Present & $29.5 \%$ & $10.6 \%$ \\
Absent & $70.5 \%$ & $89.4 \%$ \\
Burden (median) & 17 & 12 \\
Mild & $59.1 \%$ & $75.1 \%$ \\
Moderate & $28.5 \%$ & $18.8 \%$ \\
Moderate to severe & $10.2 \%$ & $6.1 \%$ \\
Severe & $2.2 \%$ & $0 \%$ \\
\hline
\end{tabular}

With regard to burden, depression symptoms and the number of medications, it was possible to observe that the group with chronic pain had higher percentages than those from no pain group, with statistically significant differences between groups (Table 2).
Out of the 320 elderly, $58.4 \%$ reported feeling pain for more than 6 months in some region of the body, representing 187 individuals. The most prevalent body locations were the lumbar region (58.8\%) and the lower limbs (58.8\%), with $56.1 \%$ of the participants reporting pain in more than one 
location of the body. According to the elderly, pain intensity in the previous week ranged between absent, weak, moderate, intense and unbearable. Regarding pain intensity, there was a predominance of moderate pain (39.0\%) and intense pain (38.6\%). The main descriptors listed by the caregivers to represent the pain were uncomfortable (92.5\%), painful (87.1\%) and persistent $(73.7 \%)$. It is worth noting that the participants could choose more than one descriptor to characterize their pain. The mean pain intensity in the previous week was 6.41 .

When comparing the groups in relation to the ACE-R domains (attention and orientation, memory, fluency, language and visuospatial skills), no statistically significant differences were found between the two groups for any of the instrument domains (Table 3).

Table 3 - Comparison between means and medians of the ACE-R instrument, according to the elderly caregiver groups with and without chronic pain - São Carlos, SP, Brazil, 2016.

\begin{tabular}{|c|c|c|c|c|c|}
\hline \multirow{2}{*}{ ACE domains } & \multicolumn{2}{|c|}{ Chronic pain $(n=187)$} & \multicolumn{2}{|c|}{ Without chronic pain $(n=133)$} & \multirow{2}{*}{$\mathbf{P}$} \\
\hline & Mean $( \pm S D)$ & Median & Mean $( \pm \mathrm{SD})$ & Median & \\
\hline Attention and orientation & $14.0( \pm 2.5)$ & 14 & $13.3( \pm 3.0)$ & 14 & 0.073 \\
\hline Memory & $15.3( \pm 6.1)$ & 15 & $14.1( \pm 6.1)$ & 15 & 0.144 \\
\hline Fluency & $6.0( \pm 2.7)$ & 6 & $5.6( \pm 3)$ & 6 & 0.289 \\
\hline Language & $18.0( \pm 5.4)$ & 19 & $18.1( \pm 5.7)$ & 19 & 0.513 \\
\hline Visuospatial skills & $10.5( \pm 3.5)$ & 10 & $10.1( \pm 3.8)$ & 10 & 0.518 \\
\hline Total ACE-R & $64.6( \pm 17.4)$ & 64 & $61.3( \pm 18.3)$ & 64 & 0.209 \\
\hline
\end{tabular}

Table 4 shows a comparison of the groups according to the ACE-R domains and the variables: education level, gender and age. The ACE-R mean was higher among men when compared to women, and the group with chronic pain presented better scores in both genders when compared those without chronic pain. However, no statistical differences were found between groups regarding these variables.

Table 4 - Comparison between ACE-R mean and medians and the variables of education level, gender and age, according to the elderly caregiver groups with and without chronic pain - São Carlos, SP, Brazil, 2016.

\begin{tabular}{|c|c|c|c|c|c|}
\hline \multirow{2}{*}{ Variables } & \multicolumn{2}{|c|}{ Chronic pain $(n=187)$} & \multicolumn{2}{|c|}{ Without chronic pain $(n=133)$} & \multirow{2}{*}{$\mathbf{P}$} \\
\hline & $\operatorname{Mean}( \pm \mathrm{SD})$ & Median & $\operatorname{Mean}( \pm \mathrm{SD})$ & Median & \\
\hline \multicolumn{6}{|l|}{ Education Level } \\
\hline Illiterate & $44.2( \pm 10.44)$ & 43.0 & $43.1( \pm 16.64)$ & 44.0 & 0.928 \\
\hline 1 to 4 years & $63.3( \pm 14.81)$ & 63.0 & $63.3( \pm 15.59)$ & 66.0 & 0.827 \\
\hline 5 to 9 years & $79.16( \pm 9.47)$ & 79.5 & $74.5( \pm 11.85)$ & 77.5 & 0.288 \\
\hline 10 or more years & $84.5( \pm 10.14)$ & 88.0 & $84.7( \pm 8.81)$ & 82.0 & 0.965 \\
\hline \multicolumn{6}{|l|}{ Gender } \\
\hline Female & $63.2( \pm 17.73)$ & 62.0 & $60.1( \pm 18.73)$ & 61.0 & 0.325 \\
\hline Male & $70.3( \pm 14.97)$ & 72.0 & $64.2( \pm 18.73)$ & 69.5 & 0.135 \\
\hline \multicolumn{6}{|l|}{ Age } \\
\hline $60-69$ & $66.9( \pm 16.93)$ & 68.0 & $65.8( \pm 17.84)$ & 70.0 & 0.132 \\
\hline $70-79$ & $64.1( \pm 17.25)$ & 62.0 & $57.4( \pm 17.43)$ & 58.5 & 0.215 \\
\hline 80 or more & $52.2( \pm 16.11)$ & 51.5 & $52.1( \pm 23.58)$ & 59.0 & 0.137 \\
\hline
\end{tabular}

\section{DISCUSSION}

Regarding the main objective of this study to verify whether there are differences in the cognitive performance of elderly caregivers with and without chronic pain, the present study did not find statistically significant differences between the groups. Studies indicate that pain and cognition are directly related factors, evidencing a possible interaction of the neural systems involved in cognition, and also being closely related to the modulation and pain perception systems. This interaction between neural structures would impair the speed with which information reaches the brain and the processing capacity of this information, predisposing patients with chronic pain to cognitive deficit ${ }^{(7-8)}$.

A review study pointed out that some neuroimaging techniques such as electroencephalography (EEG), magnetoencephalography (MEG), functional Magnetic
Resonance Imaging (fMRI) and positron emission tomography (PET) have been studied to aid in understanding the interaction between pain and cognitive processing from the neuroanatomical point of view. It is possible to observe that the somatosensory cortical areas (SI and SII), the insular cortex, the thalamus, the prefrontal cortex (PFC) and anterior cingulate cortex (ACC) were identified as the most activated brain regions during pain processing, and these regions also have important functions in cognitive processing ${ }^{(8)}$. Neuroimaging techniques are effective in assessing cognitive processing in patients with chronic pain, despite being a more expensive and robust method of data collection.

A study conducted at Northwestern University in Chicago (USA) ${ }^{(22)}$ evaluated hippocampal changes in 88 patients with chronic pain (38 with low back pain, 30 with 
complex regional pain syndrome, and 20 with osteoarthritis in the knee) and comparing them with 50 healthy subjects. Imaging tests were performed and a covariance analysis showed that subjects with low back pain and complex regional pain syndrome had significantly lower bilateral hippocampal volume in comparison with normal individuals, verifying that these alterations can contribute to learning deficit observed in these patients ${ }^{(22)}$. A limitation of this study was the non-use of neuroimaging techniques.

In order to describe the influence of chronic pain on memory performance and the interference of age in this process, a study concluded that participants with pain had worse performance on tests of working memory and verbal episodic memory when compared to the control group, and with statistically significant results ${ }^{(9)}$. However, no differences between groups regarding semantic memory and visual episodic memory were observed. The study found no differences in the comparison of chronic pain with increasing age ${ }^{(9)}$.

A cross-sectional epidemiological study carried out in a city in the south of Brazil with 1,705 elderly people over 60 years of age, aimed to investigate the prevalence of cognitive and functional impairment and its distribution in relation to sociodemographic and clinical factors such as pain ${ }^{(10)}$. The authors were surprised to identify an association between frequent pain and cognitive impairment in their results, regardless of the presence of depression, stroke, diabetes or analgesic medications. According to the authors, there is an apparent lack of data regarding the relationship between pain and cognition, being that adaptive stress and neuroanatomic mechanisms overlap, and neurochemical substrates may be related to this process ${ }^{(10)}$.

A multicenter, population-based study of 3,369 men aged 40 to 79 years, found a significant inverse proportional association between pain and psychomotor processing speed assessed using the Rey-Osterrieth Complex Figure (ROCF), the Camden Topographical Recognition Memory test (CTRM), and the Digit-Symbol Substitution test (DSST) ${ }^{(11)}$. The results showed no association with visual memory and recognition, which according to the authors may be related to the instruments used for the evaluation ${ }^{(11)}$.

In order to investigate the effects of chronic pain in the cognitive domains of 56 elderly, a study conducted in the United States concluded that pain intensity was associated with greater difficulty in numerical tests and subtests of letters, indicating that the elderly with pain had worse results on cognitive tests and in mental flexibility ${ }^{(12)}$.

In another study with 230 fibromyalgia patients older than 18 years, the authors only used the Mini-Mental State Examination (MMSE) to evaluate and compare the cognitive performance of this group with a control group. The results showed that patients with fibromyalgia had a lower score on the test with statistically significant values. The two groups were paired for sociodemographic variables ${ }^{(23)}$.

In contrast, the authors of another study observed that the MMSE test is not effective in proving cognitive deficit in patients with chronic pain. The researchers conducted a cross-sectional study to investigate the influence of pain, sedation, medications and sociodemographic characteristics on the cognitive functioning of adult and elderly patients with chronic pain, noting that the MMSE was not the most adequate instrument to detect milder forms of cognitive impairment in patients with chronic pain ${ }^{(24)}$.

In the present study, it was not possible to observe statistical differences in the cognitive domains between the two groups, disagreeing with studies found in the literature and contrary to the initial hypothesis. However, it should be emphasized that studies that investigate this relationship in the elderly are scarce and that there are no studies investigating this relationship in elderly caregivers, which makes it impossible to reach consensus in the literature about this approach. The present study presents different results from those already found, and should instigate researchers to carry out new studies on the subject, mainly with caregivers. Other more specific instruments to evaluate cognitive domains (memory, attention, orientation) should also be used; however, the literature does not present consensual evidence of more adequate instruments and tests.

Moreover, pain is a subjective and complex sensation, and there is often no linearity between the nociceptive stimulus and its perception ${ }^{(25)}$. Studies indicate that the attention that the patient pays to their pain can contribute to an increase of its intensity, impairing their daily activities, and the degree of risk for negative factors depends on the individual's belief in their own coping resources ${ }^{(25)}$.

In analyzing this theory and drawing a parallel with the results of the present study, an elderly person who cares for another elderly person at home focuses on the care and activities for the other, which may contribute to them paying less attention to their own pain, and to higher rates of coping and resilience ${ }^{(26)}$, in addition to higher levels of attention and concentration on daily tasks, which could bring up the hypothesis that caring for others may be a protective factor for cognition in elderly with pain. Thus, it is possible that being a caregiver enables the presence of some variables not found in non-caring elderly, such as attention, resilience and coping, and such peculiarities may act to protect the elderly with chronic pain from cognitive losses, which would be expected according to what has already been described in the literature. However, further studies are necessary to prove this hypothesis.

Regarding the sociodemographic characteristics of the participants, this study observed that the elderly caregivers are mainly female aged between 60 and 75 years, with low income and married/with a partner; a profile similar to that found in other studies ${ }^{(2-3,27)}$.

Women are the main executors of informal care for family members, reinforcing the historically attributed role of women with the function of providing care for the home, children and the family ${ }^{(13,27)}$. In general, studies show that caregivers perform care on an average of more than 10 hours a day and with a care time of less than 8 years ${ }^{(13,27)}$, differing from the results found in the present study in which the majority of caregivers performed care for over 10 years and for an average of under 5 hours a day. The exhaustive activity of providing care associated with the degree of dependence of the elderly can trigger high levels of burden in the caregiver with negative 
impacts on their physical and psychological well-being, especially in caregivers who take care of an elderly alone ${ }^{(13,27)}$.

Regarding sociodemographic variables, in comparing them between the groups with and without chronic pain, only the gender variable presented a statistically significant difference. No associations were observed between pain and age, education, marital status and family income variables. Some studies with adults have shown that a higher prevalence of pain in women may be associated with a number of physiological factors ${ }^{(28)}$, and other studies emphasize that women tend to report more pain than $\operatorname{men}^{(7)}$.

The prevalence of chronic pain in the elderly caregivers of the present study was $58.4 \%$. Studies indicate that the prevalence of chronic pain in Brazilian elderly can vary from $29.7 \%$ to $52.8 \%$; however, epidemiological studies with elderly people living in the community are still scarce ${ }^{(18)}$. The elderly in this study perform care activities which can generate an increase in their physical burden, predisposing them to the onset of pain. The pain sites most reported by the caregivers were lower back and lower limbs, results that corroborate other studies in the elderly ${ }^{(18)}$.

A population-based study with community elders showed that $42.1 \%$ of the participants reported severe pain intensity, followed by $25.9 \%$ who declared moderate intensity, and being located mainly in the lower limbs (34.5\%) and low back region $(29.5 \%)^{(18)}$. The results are similar to those of this investigation in which the referred pain intensity was mainly moderate and intense, which can be considered a situation of great inconvenience and an important problem in the life of caregivers, impairing their social life, as well as their care and leisure activities.

The results of this research corroborate data found in the literature in which the group with pain presented a higher prevalence of depression symptoms in relation to without pain group. A study conducted in the United Kingdom evaluated 502 participants with mean age of 65.2 years and compared the subjects according to the intensity of the pain (above or below the median), noting that the group with the highest level of pain had higher rates of depression, anxiety and worse overall health when compared to the group with low pain intensity ${ }^{(29)}$. Another fact that corroborates the literature is the higher number of continuous use medications in the group with chronic pain when compared to the group without chronic pain, with statistically significant results ${ }^{(30)}$.

Some limitations may be found in this study, one of which being the lack of more accurate assessment tools and methods to assess cognition such as neuroimaging or specific tests for memory, attention and concentration. However, the literature does not present consensual evidence of which instruments and tests are most adequate. Another limitation was not having investigated the duration of chronic pain, since there are studies that report a negative association between pain duration and cognitive performance; furthermore, not having controlled variables such as medications, depression symptoms and sleep disorders.

The relevant contribution of this study was analyzing the relationship between chronic pain and cognition in a specific population, being elderly caregivers. We hope that the results may contribute to the need for more sensitive and specific instruments, and that we can also understand subjective dimensions of the task of being a caregiver. Studies comparing groups of elderly caregivers and non-caregivers would be desirable.

\section{CONCLUSION}

The results did not show any differences between the groups regarding pain and cognition. Contrary to our expectations and the studies found in the literature, no worse cognitive performance was observed in elderly caregivers with chronic pain.

The results of the relationship between chronic pain and cognition in elderly caregivers go against the initial hypothesis; however, studies involving this specific population are still scarce. The gap in scientific knowledge about pain and cognition certainly further instigates continuity of this study, creating prospects for future research with elderly caregivers.

Furthermore, the present study allowed understanding of the sociodemographics, health status, care profile and characteristics of chronic pain in elderly caregivers attended at Family Health Units, noting that there were no differences between the groups regarding the characteristics of care and that the majority of interviewed participants reported pain, especially in the lower limbs and lower back.

\section{RESUMO}

Objetivo: Conhecer e caracterizar a dor crônica em idosos cuidadores, verificar o desempenho cognitivo dos idosos da amostra e verificar se há diferença no desempenho cognitivo de idosos cuidadores com e sem dor crônica. Método: Participaram da pesquisa pessoas com 60 anos ou mais que residiam com outro idoso no mesmo domicílio e que estavam cadastradas nas Unidades de Saúde da Família. A coleta de dados ocorreu no domicílio dos participantes. A dor foi avaliada pelo EMADOR e a cognição foi avaliada pelo ACE-R. Para as análises estatísticas foram utilizados os testes de Shapiro-Wilk e Mann-Whitney U Test. Resultados: Participaram da pesquisa 187 idosos cuidadores com dor crônica e 133 sem dor, com maior frequência de mulheres. A dor crônica esteve presente em $58,4 \%$ dos participantes. No que se refere às variáveis sociodemográficas, não houve diferença entre os grupos, com exceção da variável sexo $(p=0,025)$. Não houve diferença no desempenho cognitivo entre os idosos com dor crônica e sem dor em nenhum domínio do instrumento ACE-R. Conclusão: Os resultados contrariaram a hipótese inicial de que haveria diferença entre os grupos, no entanto, observa-se uma lacuna no conhecimento científico sobre dor crônica e cognição, principalmente em idosos cuidadores, abrindo perspectivas para investigações futuras.

Idoso; Cuidadores; Dor Crônica; Cognição; Enfermagem Geriátrica. 


\section{RESUMEN}

Objetivo: Conocer y caracterizar el dolor crónico en ancianos cuidadores, verificar el desempeño cognitivo de los ancianos de la muestra y verificar si hay diferencia en el desempeño cognitivo de ancianos cuidadores con y sin dolor crónico. Método: Participaron en la investigación personas de 60 años o más que residían con otro anciano en el mismo domicilio y que estaban registradas en las Unidades de Salud de la Familia. La recolección de datos ocurrió en el domicilio de los participantes. El dolor fue evaluado por el EMADOR y la cognición fue evaluada por el ACE-R. Para los análisis estadísticos fueron utilizadas las pruebas de Shapiro-Wilk y Mann-Whitney U Test. Resultados: Participaron en la investigación 187 ancianos cuidadores con dolor crónico y 133 sin dolor, con mayor frecuencia de mujeres. El dolor crónico estuvo presente en el 58,4\% de los participantes. En lo que se refiere a las variables sociodemográficas, no hubo diferencia entre los grupos, excepto por la variable sexo $(\mathrm{p}=0,025)$. No hubo diferencia en el desempeño cognitivo entre los ancianos con dolor crónico y sin dolor en ningún dominio del instrumento ACE-R. Conclusión: Los resultados contrariaron el supuesto inicial de que habría diferencia entre los grupos, no obstante, se observa una brecha en el conocimiento científico acerca de dolor crónico y cognición, especialmente en ancianos cuidadores, abriendo perspectivas para investigaciones futuras.

\section{DESCRITORES}

Anciano; Cuidadores; Dolor Crónico; Cognición; Enfermería Geriátrica.

\section{REFERENCES}

1. Miranda ACC, Sérgio SR, Fonseca GNS, Coelho SMC, Rodrigues JS, Cardoso CL. Avaliação da presença de cuidador familiar de idosos com déficits cognitivo e funcional residentes em Belo Horizonte-MG. Rev Bras Geriatr Gerontol. 2015; 18(1):141-50.

2. Tomomitsu MRSV, Perracini MR, Neri AL. Influência de gênero, idade e renda sobre o bem-estar de idosos cuidadores e não cuidadores. Rev Bras Geriatr Gerontol. 2013; 16(4):663-8.

3. Neri AL, Yassuda MS, Fortes-Burgos AC, Mantovani EP, Arbex FS, Torres SVS, et al. Relationships between gender, age, family conditions, physical and mental health, and social isolation of elderly caregivers. Int Psychogeriatr. 2012;24(3):472-83.

4. Benyon K, Muller S, Hill S, Mallen C. Coping strategies as predictors of pain and disability in older people in primary care: a longitudinal study. BMC Fam Pract [Internet]. 2013 [cited 2014 Oct 30];14:67. Available from: https://www.ncbi.nlm.nih.gov/pmc/articles/PMC3665454/

5. Bottega FH, Fontana RT. A dor como o quinto sinal vital: utilização da escala de avaliação por enfermeiros de um hospital geral. Texto Contexto Enferm. 2010;19(2): 283-90.

6. International Association for the Study of Pain. Pain definitions [Internet]. Washington: IASP; 2014 [cited 2014 Oct 30]. Available from: https://www.iasp-pain.org/

7. Simons LE, Elman I, Borsook D. Psychological processing in chronic pain: a neural systems approach. Neurosci Biobehav Rev. 2014;39:61-78.

8. Moriarty O, McGuire BE, Finn DP. The effect of pain on cognitive function: a review of clinical and preclinical research. Prog Neurobiol. 2011;93(3):385-404.

9. Oosterman JM, Derksen LC, van Wijck AJ, Veldhuijzen DS, Kessels RP. Memory functions in chronic pain: examining contributions of attention and age to test performance. Clin J Pain. 2011;27(1):70-5

10. Lopes MA, Xavier AJ, D'Orsi E. Cognitive and functional impairment in an older community population from Brazil: the intriguing association with frequent pain. Arch Gerontol Geriatr. 2016;66:134-9.

11. Lee DM, Pendleton N, Tajar A, O'Neill TW, O'Connor DB, Bartfai G, et al. Chronic widespread pain is associated with slower cognitive processing speed in middle-aged and older European men. Pain. 2010;151(1):30-6.

12. Karp JF, Reynolds CF, Butters MA, Dew MA, Mazumdar S, Begley AE. The relationship between pain and mental flexibility in older adult clinic patients. Pain Med. 2006;7(5):444-52.

13. Gratão ACM, Vendrúscol TRP, Talmelli LFS, Figueiredo LC, Santos JLF, Rodrigues RAP. Sobrecarga e desconforto emocional em cuidadores de idosos. Texto Contexto Enferm. 2012;21(2):304-12.

14. Merskey NB. Classification of chronic pain: descriptions of chronic pain syndromes and definitions of pain terms prepared by the International Association for the Study of Pain. 2nd ed. Seattle: IASP; 1994.

15. Lino VTS, Pereira SEM, Camacho LAB, Ribeiro Filho ST, Buksman S. Adaptação transcultural da Escala de Independência em Atividades da Vida Diária (Escala de Katz). Cad Saúde Pública. 2008;24(1):103-12.

16. Santos RL, Virtuoso JSJ. Confiabilidade da versão brasileira da escala de atividades da vida instrumentais diária. Rev Bras Promoção Saúde. 2008;21(4):290-6.

17. Sousa FAEF, Pereira LV, Cardoso R, Hortense P. Escala Multidimensional de Avaliação de Dor (EMADOR). Rev Latino Am Enfermagem. 2010;18(1):3-10.

18. Pereira LV, Vasconcelos PP, Souza LAF, Pereira GA, Nakatani AYK, Bachion MM. Prevalência, intensidade de dor crônica e autopercepção de saúde entre idosos: estudo de base populacional. Rev Latino Am Enfermagem. 2014;22(4):662-9.

19. Carvalho VA, Barbosa MT, Caramelli P. Brazilian version of Addenbrooke's Cognitive Examination in the diagnosis of mild Alzheimer disease. Cogn Behav Neurol. 2010;23(1):8-13.

20. Almeida O, Almeida SA. Confiabilidade da versão brasileira da Escala de Depressão em Geriatria (GDS) versão reduzida. Arq Neuropsiquiatr. 1999;57(2-B):421-6.

21. Scazufca M. Brazilian version of the Burden Interview scale for the assessment of burden of care in carers of people with mental illnesses. Rev Bras Psiquiatr. 2002;24(1):12-7. 
22. Mutso AA, Radzick D, Baliki MN, Huang L, Banisadr G, Centeno MV, et al. Abnormalities in hippocampal functioning with persistent pain. J Neurosci. 2012; 32(17):5747-56.

23. Rodríguez-Andreu J, Ibáñez-Bosch R, Portero-Vázquez A, Masramon X, Rejas J, Gálvez R. Cognitive impairment in patients with Fibromyalgia syndrome as assessed by the Mini-Mental State Examination. BMC Musculoskeletal Disord. 2009;10:162.

24. Sjøgren P, Christrup LL, Petersen MA, Højsted J. Neuropsychological assessment of chronic non-malignant pain patients treated in a multidisciplinary pain centre. Eur J Pain. 2005;9(4):453-62.

25. Wiech K, Ploner M, Tracey I. Neurocognitive aspects of pain perception. Trends Cogn Sci. 2008;12(8):306-13.

26. Boeiro P. Cuidar no lugar: um apelo ao sentido de coerência e à resilência [editorial]. Rev Port Med Geral Fam. 2016;32(1):6-8.

27. Cardoso L, Vieira VM, Ricci MAM, Mazza RS. The current perspectives regarding the burden on mental health caregivers. Rev Esc Enferm USP. 2012;46(2):513-7.

28. Martinez-Jauand M, Sitges C, Femenia J, Cifre I, Gonzalez S, Chialvo D, et al. Age-of-onset of menopause is associated with enhanced painful and non-painful sensitivity in fibromyalgia. Clin Rheumatol. 2013;32(7):975-81.

29. Benyon K, Muller S, Hill S, Mallen C. Coping strategies as predictors of pain and disability in older people in primary care: a longitudinal study. BMC Fam Pract [Internet]. 2013 [cited 2014 Oct 30];14:67. Available from: https://www.ncbi.nlm.nih.gov/pmc/articles/PMC3665454/

30. Dellaroza MSG, Furuya RK, Cabrera MAS, Matsuo T, Trelha C, Yamada KN, et al. Caracterização da dor crônica e métodos analgésicos utilizados por idosos da comunidade. Rev Assoc Med Bras. 2008;54(1):36-41. 